Teaching \& Learning (2012) 7(2), 79-96

\title{
Advancing from a Diary Cartoon Novel to Young Adult Fiction: Exploring Issues of Gender and Power with Girls with Reading Difficulties
}

\author{
VERA WOLOSHYN \\ Associate Professor \\ Brock University \\ NANCY TABER \\ Brock University \\ LAURA LANE \\ Brock University
}

\begin{abstract}
Learning disabilities are often referred to as invisible exceptionalities, with reading difficulties representing the most common form of learning disability. Girls with reading difficulties are often overshadowed by their male counterparts and as such overlooked for intervention programs. In this article, we detail our research conducting a book club intended to assist four preadolescent girls who struggle with reading to engage and critique text in context of societal issues related to gender and self-empowerment. We outline how we used recursive, higher-level question prompts and corresponding discussion-based activities to advance from reading a diary cartoon novel (Dork Diaries) to a more difficult young adult novel (The Hunger Games). Our findings present the girls' responses to the texts and highlight the importance of holding ongoing structured conversations and engaging youth in a societal gendered critique.
\end{abstract}

\section{Reading Difficulties, Gender, and Book Clubs}

Few would disagree that the ability to comprehend or derive meaning from text is critical for academic success. Similarly, the ability to position derived information critically with reference to self and others is an important skill in developing an awareness of sociocultural issues (Gavelek \& Bresnahan, 2009; Zipes, 2002). Thinking critically about text encourages students to consider different points of view and challenge understandings, with the goal of transforming beliefs and behaviours of self and others (McLaughlin \& DeVoogd, 2011). Not surprisingly, these cognitive processes are often difficult for many students to master, especially those with reading difficulties.

In Canada, approximately two in every ten elementary-grade students receive some form of special education, with the majority of these students experiencing reading difficulties 
(Statistics Canada, 2006). Such learning challenges are often referred to as invisible, relative to other exceptionalities associated with demonstrative overt indicators. Those who are identified for intervention tend to receive it within the first three years of schooling (Ontario Ministry of Education, 2005; Snow, Burns \& Griffin, 1998). Unfortunately, early interventions alone are often insufficient to promote sustained reading proficiency, with older students requiring continued support (Biancarosal, Sullivan Palincsar, Deshler, \& Nair, 2007; Fletcher, Lyon, Fuchs, \& Barnes, 2007).

More positively, there is substantial literature documenting effective reading instruction and intervention (IRA, 2007; RAND, 2002), with this programming being especially effective when provided explicitly and with authentic text. There is also substantial evidence documenting the important roles of language, social interactions and culture for the comprehension of text (The New London Group, 1996; Gavelek \& Bresnahan, 2009). Such sociocultural theories of literacy acknowledge the situated nature of reading and the co-construction of knowledge as influenced by readers' participation in multiple, and sometimes inconsistent, social and cultural Discourses (e.g., primary home-based home Discourses versus secondary school-based Discourses; Gee, 2000, 2001).

Book clubs provide a venue in which educators can assist students to become better readers (Casey, 2008; Certo, Moxley, Reffitt \& Miller, 2010; Whittingham \& Huffman, 2009), while encouraging them to discuss text as a way of engaging in societal critique (Polleck, 2010, 2011; Smith, 2000; Twomey, 2007; Vyas, 2004). Book clubs typically adopt small-group, student-directed structures, organized around gender, age, or genre and are hosted either within or outside classrooms (Polleck, 2010, 2011; Smith, 2000; Vyas, 2004). Participation in such discussions such as those promoted in book clubs is especially important for female students who experience reading difficulties, as they may be unversed in school Discourses related to expectations, culture, and literacy (Gavelek \& Bresnahan, 2009), and overlooked for intervention (Liederman, Kantrowitz \& Flannary, 2005; Graff, 2009; Sprague \& Keeling, 2009), with their voices often overshadowed by their male counterparts (Clarke, 2007; Osler, 2006). Equally important, these discussions can assist students in identifying how female characters are often represented in stereotypical and/or peripheral manners in text. For instance, females are more likely to be presented as less central and action-oriented than males (Diekman \& Murnen, 2004; McCabe, Fairchild, Grauerholz, Pescosolido \& Tope, 2011), obsessed about body image 
(Younger, 2003), and desiring male attention (McInally, 2008). Even when females are presented as strong self-determining protagonists who confront sexism and other forms of discrimination, there is little recognition of the societal influences that work to marginalize women (Hubler, 2000).

This article synthesizes various aspects of our ongoing research about how book clubs can be used to facilitate girls who struggle with reading, to engage and critique text in context of societal issues related to gender and self-empowerment. Specifically, we sought to further understand how these girls perceive and critique gendered norms and power relations, by using a diary cartoon novel, to progress to reading and critiquing a much more difficult prose novel.

\section{Methodology}

We used a case study methodology to explore the experiences of four preadolescent girls participating in an after-school book club intended to promote girl empowerment. Case studies involve an in-depth exploration of an activity, event, process, or individuals based on extensive data collection (Merriam, 1998, 2002). Book club sessions followed the format proposed by Raphael and colleagues (Raphael \& McMahon, 1994) that includes the use of literature that connects to the participants' lives, a small-group format, student-directed discussions, higherlevel thinking questions, written responses (e.g., journal writing, authentic projects), and directed strategic instruction as required (See Author, Author, \& Author, 2012 for an in-depth discussion of the tensions involved in this research project in relation to the researchers' positionalities as participant-observers, facilitators of girl empowerment, and scholars.).

\section{Participants}

The participants were four girls in grades 5-7 with reading difficulties, with each girl selecting a pseudonym that was used for data reporting. The girls were Caucasian and from families that were low-to-mid and mid socioeconomic status. Taylor attended a small public school and lived in a blended family with several siblings. She played several sports and described herself as having many friends but as experiencing academic difficulties. Aryton was adopted and lived with her parents and younger brother. She described herself as small but indicated that she used her size to her advantage in sports such as wrestling where she won several competitions. She also described herself as a "tag-along" in the school 
playground. Madison was an only child whose family moved to Ontario from an eastern province. She described herself as a unique and creative individual as well as a "loner" who conversed with classmates across various social cliques, but did not belong to any one group. Bridget was the youngest of three girls in her family and participated in basketball and dance lessons, and enjoyed reading fiction. Throughout the course of the book club sessions, she confided to her parents that a classmate was "bullying" her at school and that she wanted their assistance in bringing these instances to her teacher's attention. Collectively, the girls' reading performance scores were two to three years below grade level, with listening comprehension at or slightly below grade level, as determined by performance scores on the Ekwall/Shanker Reading Inventory $5^{\text {th }}$ Edition (Shanker \& Cockrum, 2009), and as confirmed through academic and/or psychometric reports.

\section{Book Club Texts}

The first book club program consisted of six two-hour sessions held weekly and focused on a critical analysis of Dork Diaries: Tales from a NOT-SO-Fabulous Life (Russell, 2009). The girls selected the text as one of three text options including The Skin I'm In (Flake, 1998/2007) and Ella Enchanted (Levine, 1997). The second book club session consisted of four two-hour sessions held over an eight-week interval and focused on a critical analysis of The Hunger Games (Collins, 2008). The girls requested to read this text based on its popularity among their peers and their positive experiences with the first book club session. The girls were provided with the respective published CD recordings of the texts to facilitate their independent reading and accommodate any decoding difficulties they may encounter.

Dork Diaries: Tales from a NOT-SO-Fabulous Life is narrated through the diary of the female protagonist Nikki Maxwell, a 14-year-old girl who is a new student at a private middle school. Nikki struggles to fit in with the popular girls, who are lead by MacKenzie, and who possess the latest designer clothes, accessories, and gadgets. Nikki eventually befriends two other girls who share her love of reading and art. The book discusses various conflicts that arise between Nikki and Mackenzie, as well as between Nikki and her friends. Themes related to popularity, victimization, self-acceptance, and belonging, are readily found throughout the text. According to the Fountas and Pinnell (2010-2011) reading levels, the text is estimated to be 
within the grade-5 reading level (Level T). We deemed the text to be within the girls' instructional reading levels as a function of the extensive incorporation of visuals (cartoon images) and relatively limited use of print.

The Hunger Games is narrated through the female protagonist Katniss Everdeen, a 16year-old girl who provides for her younger sister and mother following the death of her father. Set in a dystopian future, the text chronicles Katniss' participation in the Hunger Games and her struggle to survive under the harsh rule of the wealthy Capitol. To punish the districts for a lost rebellion, reinforce the power of the Capitol, and entertain its citizens, a girl and boy from each of the 12 districts are selected randomly to participate in the Games. These tributes are then sent to a televised arena to fight to the death. The book focuses on Katniss' survival during the games, as well as her evolving relationship with her co-tribute Peeta. Themes contained throughout the book related to self-determinism, cooperation, power, romance, and violence.

We recognized that this text represented a considerably more complex read than the cartoon diary, with its readability being estimated with the Grade 6-8 level (Levels X-Z), according to the Fountas-Pinnell reading levels. Specifically, the novel provided no illustrations and was dense with print (estimated at approximately 100,000 words). We conceded to using the text based on the girls' request to read and discuss it, recognizing that learners' interest and motivation to interact can largely influence their reading success (Whittingham \& Huffman, 2009).

Book club format and activities. Book club discussions included reviewing and predicting activities, clarifying and questioning while listening to and/or reading text, and summarizing exercises. The girls also completed a number of activity-based exercises (e.g., drama and role-playing, visual representing, journaling, dilemma and game-based questioning). The girls were encouraged to generate text-to-text, text-to-self, and text-to-world connections throughout the activities and discussions. We highlight some of the activities and discussion prompts that we used to challenge the girls' notions of stereotypical feminine representations (such as beauty and heteronormativity), power, and control. In an effort to increase the transparency of the book club format itself, we provide a detailed overview of the questions and activities used throughout the book club sessions, demonstrating how we related content and 
themes from the diary cartoon novel and the more difficult prose novel. It is our hope that others may be able to adapt our work to their own contexts.

Providing the girls with recursive, higher-level thinking questions and encouraging them to relate their responses within and beyond the texts were central components of the book club sessions (see Table 1 for a list of these questions). We presented these questions repeatedly and in a recursive manner within and across the sessions, encouraging the girls to reflect, extend, and in some cases, challenge their previous ways of thinking. For instance, we challenged the girls to consider "What does it mean to be a girl?" and "What does it mean to be popular/hold power?" throughout their readings of the Dork Diaries as well as The Hunger Games. We believed that the girls' abilities to participate in a sociocultural critique of gender and power would be enhanced through the use of such recursive questions, as they require learners to respond to open-ended prompts, while forming connections between their prior knowledge and new information.

Table 1

Higher-level, recursive question prompts used to challenge stereotypical feminine representations and notions of beauty, heteronormativity, and power

\begin{tabular}{|l|l|}
\hline Dork Diaries & The Hunger Games \\
\hline What does it mean to be a girl? & What does it mean to be a girl? \\
What do they look like? & What does she look like? \\
Does Nikki need a boyfriend? & Does Katniss need a boyfriend? \\
What does it mean to be a popular? & What does it mean to be wealthy? \\
How do popular girls behave? & (Capitol/Districts) \\
How do girls gain and maintain popularity? & Respond to the allocation of resources? \\
\hline
\end{tabular}

The girls also participated in a number of planned activities intended to support their discussions and critiques of gender and power. These activities similarly were intended to help the girls make connections between the texts and their daily lives. For instance, while reading Dork Diaries, the 
girls participated in a number of problem solving activities intended to facilitate their sociocultural critique of gender and power. These activities involved having the students assume the roles of the female characters within the text and generate alternative responses that challenged notions of the feminine beauty ideal and power, as defined by social cliques and material wealth. Similarly, while reading The Hunger Games, the girls participated in several resource allocation activities intended to emphasis power dynamics associated with resource allocation, as well as activities that questioned the necessity of heteronormative relationships. Table 2 provides an overview of some of the activities used throughout the book club sessions.

Table 2

Sample activities designed to challenge stereotypical feminine representations as related to notions of beauty, heteronormativity, and power

\begin{tabular}{|l|l|}
\hline \multicolumn{1}{|c|}{ Dork Diaries } & \multicolumn{1}{|c|}{ Activity Description } \\
\hline "THIS IS SO NOT ME!" & Girls complete profile identifying personal \\
characteristics, attributes and strengths. \\
What would MacKenzie say? & Girls generate scripts consistent with the main \\
(e.g., p. 30) & antagonist response pattern, as well as possible \\
"I Am" and "Nothing Girl" poetry & Girls provide a personal response to poetry \\
reading (e.g., p. 220) & readings related to self-identity and gender. \\
"Inner Voice" versus "Outer & Girls respond to quotations from the text, \\
(e.g., p. 101) & Girls create cafeteria maps representative of social \\
& norms in their school. \\
\hline
\end{tabular}




\begin{tabular}{|c|c|}
\hline $\begin{array}{l}\text { Voice" } \\
\text { (e.g., p. 110) }\end{array}$ & $\begin{array}{l}\text { differentiating appropriate public responses versus } \\
\text { their personal thoughts }\end{array}$ \\
\hline $\begin{array}{l}\text { "Chicken" or "Champion" } \\
\text { (e.g., p. 48) }\end{array}$ & $\begin{array}{l}\text { Girls are provided with/generate scripted dilemmas } \\
\text { reflective of their daily lives and indicate how } \\
\text { either a chicken or champion would respond. }\end{array}$ \\
\hline The Hunger Games & Activity Description \\
\hline $\begin{array}{l}\text { Character Profiles } \\
\text { (e.g., pp. 3-20) }\end{array}$ & $\begin{array}{l}\text { Girls use descriptive words/images to generate } \\
\text { character profiles of main characters in text. }\end{array}$ \\
\hline $\begin{array}{l}\text { Capitol and District Collages } \\
\text { (e.g., p. 59) }\end{array}$ & $\begin{array}{l}\text { Girls create collages exemplifying disparity of } \\
\text { resources. }\end{array}$ \\
\hline $\begin{array}{l}\text { Dove Evolution Commercials } \\
\text { (e.g., p. } 61 \text { ) }\end{array}$ & $\begin{array}{l}\text { Girls view and discuss the styling and preparation } \\
\text { and general "make over" of a commercial model. }\end{array}$ \\
\hline $\begin{array}{l}\text { “He Loves Me, He Loves Me } \\
\text { Not" Daisy (e.g., p. 247) }\end{array}$ & $\begin{array}{l}\text { Girls are provided with quotations from text and } \\
\text { place on coloured petals representative of Katniss' } \\
\text { romantic status with Peeta (loves him, loves him } \\
\text { not, uncertain). }\end{array}$ \\
\hline $\begin{array}{l}\text { "You Get Cookies", "You Get } \\
\text { Dry Bread" Resource Simulation }\end{array}$ & $\begin{array}{l}\text { Three girls respond to being provided with a snack } \\
\text { of bread and water whereas another receives one of }\end{array}$ \\
\hline
\end{tabular}




\begin{tabular}{|l|l}
\hline (e.g., p. 202) & sweets and juice.
\end{tabular}

\section{Data Collection and Analysis}

In addition to attending the book club sessions, the girls participated in pre-session and post-session individual interviews, with each interview lasting between 60-90 minutes. As part of these sessions, girls were asked to elaborate on their understanding of the texts, especially with respect to notions of gender and power. They were also encouraged to discuss connections between the texts and their daily lives. All interviews and book club sessions were audio recorded and transcribed for subsequent analysis. Analysis was completed using Merriam's (1998) case study application of Glaser and Strauss's (1967) constant comparative method. We reviewed all data independently, meeting to discuss our interpretations and arrive at a shared understanding of the themes and associated implications.

\section{Reading Engagement and Critique}

We believe that these book-club conversations contributed positively to the students' evolving concepts of self as readers and as girls (Author, Author \& Author, 2013). By responding to critical questions across the texts, we were able to begin to problematize several aspects of power and gendered representations within the text and society. For the purpose of the research described here, we narrow our findings to those directly related to the girls' emerging critique of expectations for participation in heternormative relationships and a feminine beauty ideal, as performed through the central female characters within each novel. Our purpose of presenting the data here is not to analyze it per se, but to assist educators in understanding the outcome of our book club approach, and how the format and activities led to the participants' engagement with reading and critique.

\section{Critiquing Power}

The girls demonstrated emerging abilities to identify and challenge concepts of power in the context of the text and their own lives. In their reading of both texts, the girls seemed acutely aware how the antagonists of each novel held and used material wealth and resource to gain control over others. Specifically, in Dork Diaries, they recognized that McKenzie's popularity was largely based on her wealth and ability to possess the latest fashions and accessories. In The 
Hunger Games, they identified the Capitol as a sinister "bully" that withheld resources from the districts, in order to maintain totalitarian control, equating bullying across texts. As Bridget stated, "The Capitol is the girl [MacKenzie]... the mean one" (Bridget).

The Capitol is a bully - President Snow is a bully ... I think they're mean [Capitol]... and they have food.... they're richer. (Ayrton)

The capitol... it's more wealthy and rich... they have a different life style just because like they get, they have like all this fancy food and stuff... it's like really bad, they're making people kill each other for excitement... (Taylor)

However, when initially challenged about how they might respond to oppressive power, or what they identified as "bullying", the girls provided initial solutions that were either fantastical (Dork Diaries) or evasive (The Hunger Games).

Go over to MacKenzie and say, 'Hey! Can I talk to you for a second?' And then say, 'Close your eyes,' and make sure everybody's watching, and you walk her right into the boys' change room and say, 'Oh, MacKenzie, I'm so sorry,' and lock the door and make sure she can't come out." (Bridget)

Their responses became more reasoned as illustrated in Bridget's suggestion that they could speak to an antagonist directly, "After she [MacKenzie] starts feeling like us, we'd tell her, 'How do you like that? That's how you've been treating us."' Other suggestions included avoiding mean girls, laughing at bullying behaviours, making alternative friends, advocating for others, being empathetic, and being self confident. They concluded that, while they needed to advocate for themselves, this could not be at the expense of others. Bridget's mother poignantly provides an example of this transformation when she explained how, after sustained silence, Bridget decided to inform her parents and teacher of being bullied in school, which led to a remediation of the situation.

The girls carried their thinking forward in the reading of The Hunger Games. While they were empathetic to the tributes circumstances, they identified the potential power of the 
collective, and questioned whether the districts might resist (either by refusing to fight or actively rebelling).

[Instead of fighting, the characters should] run and hide... climb, climb, climb... jump from tree to tree. (Bridget)

If they didn't fight the games wouldn't go on.... they shouldn't have tried to kill each other they should have just stopped... decide... let's not fight. (Ayrton)

The solution is.... sitting down, talking about it, compromise, standing your ground. (Madison)

As can be seen from these quotations, their responses varied from hiding to challenging power through cooperation.

\section{Critiquing Expectations for Heteronormative Relations}

The girls' ability to critique notions of emphasized femininity including participation in heteronormative relationships, evolved throughout the reading of the two texts. For instance, in the reading of Dork Diaries, they maintained that Nikki's crush on Brandon was a notable, yet normalized element of girls' behaviours in the text, without questioning or critiquing it.

At the beginning Nikki wants to be friends with MacKenzie. And then she has a crush on the same guy, which, A.K.A., should never happen. One girl, one boy. (Bridget)

All the girls were going to go flirt with the boys.... The boys liked her [Nikki's tattoo artwork], but if they didn't like her, the girls are gonna say well, 'I don't wanna hang out if you don't like her.' (Madison)

More positively, while they were empathetic to Katniss' need to appear as "star crossed lovers" in order to survive in The Hunger Games, they questioned whether she truly needed to be part of a heteronormative relationship. 
They had to make up some story that they were like madly in love. I think she was starting to kind of have a crush on him but I don't think she really liked him that much. She probably thought of him more as a friend... I don't think she would have been kissing him and stuff if she needn't need to get the sponsors, and I think she would have maybe done stuff differently... not made a big show. (Taylor)

She's mixed up... When Peeta told the people that he loved her, she pretended that she did. (Madison)

They also connected the content of the books to that of other artefacts of popular culture.

In a lot of movies all the teenagers like to have a lot of boyfriends and lots of crushes on people and stuff. (Taylor)

As might be expected, the girls were able to engage in a beginning critique of the need for romance, while also normalizing it.

\section{Critiquing Feminine Beauty Ideal}

Similarly, the girls demonstrated an emerging ability to critique concepts related to the feminine beauty ideal. They identified MacKenzie as a character craving male attention and preoccupied with image, "She [MacKenzie] always wanted to have him [Brandon] say, 'You're pretty. You're gorgeous,' and all that..." (Madison). When discussing The Hunger Games, in an activity connecting Dove Evolution (2012) to Katniss' makeover, Taylor independently brought up MacKenzie, stating:

It's like on this show I watch. I forget what it's called, but it's like McKenzie, there's these people who would follow her around a lot, ...there's probably a popular girl in her school that's making fun of her color of her hair. 
Taylor's comments indicate that she understands the social pressure that girls and women are under to look a certain way. At the same time, she also accepts it. All the girls struggled to critique the feminine beauty ideal, especially in context of their own daily lives.

She [the Dove model] wanted her hair to be blonde so why can't she just dye it? (Bridget)

We wanna look nice, but we don't wanna look like too over-done... (Madison)

In contrast, the girls admired Katniss' strength, hunting expertise, and general lack of concern for her physical appearance, sometimes viewing her as a boy, acknowledging differences between how gender was performed in Dork Diaries and The Hunger Games. This may have been due to the fact that, while the former is a realistic book, the latter is set in a dystopian future.

I like how she [Katniss] was really strong.... (Taylor)

Like, she took her sister's spot... and that probably took a lot [strength, courage]... She cares about her family... She... hunts and stuff... she doesn't just like stay at home with her sister and make medicine and... food and... more household stuff... She goes outdoors and does physical stuff. (Taylor)

She [Katniss] acts like a, a boy but wasn't. She wasn't visually a boy. She hunted... she didn't care what she looked like. (Bridget)

I think she's [Katniss] strong and you better not get in her way.... Sometimes I think she's a boy in the scenes. (Madison)

As we encouraged the girls to continue to contemplate and debate these positions, they again made comments about societal pressures associated with appearance and heteronormative relationships, conceding that all girls should be provided with choices, "They [girls] can wear makeup if they want to. They shouldn't have to but if they want to" (Bridget). Furthermore, they 
also articulated the importance of accepting themselves instead of conforming to societal expectations.

Don't listen to them. Be your own person. If you're happy, that's who you are, everyone should accept you for that. (Taylor)

I got to be my own person. (Aryton)

He [my friend] always says to me at school when I'm sitting there... He says, 'You're really weird, Madison.' I'm like, well, that's a good thing. If I'm not weird, I'm normal. Which is worse? I'd say being normal (Madison).

Overall, we recognize that these conversations are preliminary and somewhat partial, especially in context of a gendered critique. Specifically, the girls' responses demonstrate the pervasiveness and tenacity of gendered beliefs as embedded in popular culture and society, and underscore the continued importance of engaging youth in a societal critique.

More positively, we believe that we were successful in promoting girl empowerment at a micro level, by helping the girls discuss the gendered aspects of their lives that they may take for granted. These experiences serve to remind educators and other adults who work in literacy, about the value of holding structured conversations with youth, as well as reminding them that these efforts must be ongoing. Most pertinent to this article, we believe that the ways in which the girls were able to perceive the interconnections between the diary cartoon novel, more difficult prose novel, and their own lives, was very powerful in helping them to engage in not only reading, but in a sociocultural gendered critique. They were able to see beyond the issues in the book in order to connect them to their daily life, and began to critique how gender and power function in literature and reality.

\section{Conclusions and Implications}

The findings of this study extend and confirm previous research demonstrating the potential of structured book-club discussions and activities for promoting reading competence and sociocultural critique (Polleck, 2010; Twomey, 2007). In direct contrast to comments made 
prior to the program where the girls described themselves as poor readers who struggled to decode text and derive meaning from it, at the end of the research they perceived themselves as more capable readers who enjoyed reading, valued the book club environment, and the opportunity to discuss the texts [see Author et al., 2013 for a more detailed discussion of the participants' changing perspectives on reading].

As this book club was an after-school activity, at an off-school site, with a small group of participants, we were able to engage with the girls and the content in ways that may be challenging for educators in school settings. In particular, these girls participated in an in-depth, personalized learning environment over several months. There was no stigma associated with the group as all girls experienced some form of reading difficulties, volunteered to participate, and were guaranteed confidentiality. The fact that the group was not affiliated with school allowed them to engage in reading without assessment or regulation.

While we acknowledge that a group of this sort can be resource-intensive, it points to the importance of focusing on the needs of those who face marginalization due to an intersection of gender and reading difficulties. We hope that this research provides an example of the ways in which educators can support those with reading difficulties.

Vera Woloshyn is a Professor in the Faculty of Education at Brock University. Her research interests include ableism in children's literature, and developing and implementing effective literacy and learning programs for children and adults, especially those with learning exceptionalities.

Nancy Taber is an Associate Professor in the Faculty of Education at Brock University. Her research interests include sociocultural issues in children's fiction; learning masculinities and femininities in everyday life; and, gender in war/militaries/militarism.

Laura Lane is a PhD Candidate in the Faculty of Education at Brock University. Her research interests include social/cultural/political contexts of education; forms of capital and privileged culture; and, gender performance and social media.

\section{References}

Biancarosal, G., Sullivan Palincsar, A., Deshler, D. D., \& Nair, M. (2007). Adolescent literacy: Myth and realities. In D. Deshler, A. Sullivan Palincsar, G. Biancarosa, \& M. Nair (Eds.), Informed choices for struggling adolescent readers: A research-based guide to 
instructional programs and practices (pp. 11-36). Newark, DE: International Reading Association.

Casey, H. K. (2008). Engaging the disengaged: Using learning clubs to motivate struggling adolescent readers and writers. Journal of Adolescent \& Adult Literacy, 52(4), 284-294.

Certo, J., Moxley, K., Reffitt, K., \& Miller, J. A. (2010). I learned how to talk about a book: Children's perceptions of literature circles across grade and ability levels. Literacy Research and Instruction, 49(3), 243-263.

Clarke, L. W., \& Holwadel, J. (2007). "Help! What is wrong with these literature circles and how can we fix them?" The Reading Teacher, 61(1), 20-29.

Collins, S. (2008). The hunger games. New York, NY: Scholastic Press.

Diekman, A., \& Murnen, S. (2004). Learning to be little women and little men: The inequitable gender equality of nonsexist children's literature. Sex Roles, 50(5/6), 373-385.

Dove. (2012). Evolution: A Dove film [online]. Available from http://www.dove.ca/en/TipsTopics-And-Tools/Videos/default.aspx

Flake, S. G. (1998/2007). The skin I'm in. New York, NY: Jump at the Sun.

Fletcher, J. M., Lyon, G. R., Fuchs, L. S., \& Barnes, M. A. (2007). Learning disabilities: From identification to intervention. New York, NY: The Guilford Press.

Fountas, I. C., \& Pinnell, G. S. (2010-2011). Leveled book list K-8+. Portsmouth, NH: Heinemann.

Gavelek, J., \& Breshahan, P. (2009). Ways of meaning making: Sociocultural perspectives on reading comprehension. In S. E. Isreal \& G. G. Duffy (Eds.), Handbook of research on reading comprehension (pp. 140-176). New York, NY: Routledge.

Gee, J. P. (2000). Discourse and sociocultural studies in reading. In M. Kamil, P. Mosenthal, P. Pearson, \& R. Barr (Eds.), Handbook of reading research (pp. 195-207). Mahwah, NJ: Erlbaum.

Gee, J. P. (2001). Reading as situated language: A sociocultural perspective. Journal of Adolescent and Adult Literacy, 44(8), 714-725.

Glaser, B. G., \& Strauss, A. L. (1967). The discovery of grounded theory. Chicago, IL: Aldine.

Graff, J. M. (2009). Girls as "struggling readers": Delineating the sociopolitical and sociocultural terrains of books and reading. Reading Research Quarterly, 44(4), 357-359.

Hubler, A. E. (2000). Beyond the image: Adolescent girls, reading, and social reality. NWSA Journal, 12(1), 84-99.

International Reading Association. (2007). Teaching reading well: A synthesis of the International Reading Association's research on teacher preparation for reading instruction. Newark, DE: International Reading Association. (www.reading.org)

Lane, L., Taber, N., \& Woloshyn, V. E. (2012). Negotiating tensions between researching, facilitating, and critiquing gender: Exploring institutional and feminist influences. Forum: Qualitative Social Research, 13(3). http://nbnresolving.de/urn:nbn:de:0114-fqs 1203100

Levine, G. C. (1997). Ella enchanted. New York, NY: Harper Collins.

Liederman, J., Kantrowitz, L., \& Flannary, K. (2005). Male vulnerability to reading disability is not likely to be a myth: A call for new data. Journal of Learning Disabilities, 38(2), 109120.

McCabe, J., Fairchild, E., Grauerholz, L., Pescosolido, B. A., \& Tope, D. (2011). Gender in twentieth-century children's books: Patterns of disparity in titles and central characters. Gender and Society, 25(2), 197-226. 
McInally, K. (2008). Who wears the pants? The (multi)cultural politics of The sisterhood of the traveling pants. Children's Literature in Education, 39(3), 187-200.

McLaughlin, M., \& DeVoogd, G. (2011). Critical literacy as comprehension: Understanding at deeper levels. In D. Lapp \& D. Fisher (Eds.), Handbook of research on teaching the English language arts ( $3^{\text {rd }}$ ed.) (pp. 278-282). New York, NY: Routledge.

Merriam, S. B. (1998). Qualitative research and case study applications in education. San Francisco, CA: Jossey-Bass.

Merriam, S. B. (2002). Qualitative research in practice: Examples for discussion and analysis. San Francisco, CA: Jossey-Bass.

Ontario Ministry of Education. (2005). Education for all: The report of the expert panel on literacy and numeracy instruction for students with special education needs, kindergarten to grade 6. Retrieved from: http://www.edu.gov.on.ca/eng/document/reports/speced/panel/speced.pdf

Osler, A. (2006). Excluded girls: Interpersonal, institutional and structural violence in schooling. Gender and Education, 18(6), 571-589.

Polleck, I. N. (2010). Creating transformational spaces: High school book clubs with inner-city adolescent females. The High School Journal, 93(2), 50-68.

Polleck, I. N. (2011). Using book clubs to enhance social-emotional and academic learning with urban adolescent females of color. Reading \& Writing Quarterly, 27, 101-128.

Rand Reading Study Group. (2002). Reading for understanding: Toward an R\&D program in reading comprehension (pp. 61-72). Rand Corporation.

Raphael, T. E., \& McMahon, S. I. (1994). Book clubs: An alternative framework for reading instruction. The Reading Teacher, 48(2), 102-116.

Russell, R. (2009). Dork diaries: Tales from a not-so-fabulous life. North Richland Hills, TX: Aladdin Publishing

Shanker, L., \& Cockrum, W. (2009). Ekwall/Shanker reading inventory (5 ${ }^{\text {th }}$ ed.). Boston, MA: Allyn \& Bacon.

Smith, S. A., (2000). Talking about the "real stuff": Explorations of agency and romance in an all-girls book club. Language Arts, 78(1), 30-38.

Snow, C. E., Burns, M. S., \& Griffin, P. (Eds.). (1998). Preventing difficulties in young children. Washington, DC: National Institute for Child Health and Human Development.

Sprague, M. M., \& Keeling, K. K. (2009). Paying attention to girls' literacy needs. In K. D. Wood \& W. E. Blanton (Eds.), Literacy instruction for adolescents: Research-based practices (pp. 187-209). New York, NY: The Guilford Press.

Statistics Canada. (2006). Participation and activity limitation survey 2006: Tables. Retrieved from http://www.statcan.gc.ca/pub/89-628-x/2007003/4125092-eng.

Taber, N., Woloshyn, V., \& Lane, L. (2012). Food chains, mean girls, and revenge fantasies: Relating fiction to life in a girls' book club. Brock Education Journal, 22(1), 26-40.

The New London Group. (1996). A pedagogy of multiliteracies: Designing social futures. Harvard Education Review, 66(1), 60-92.

Twomey, S. (2007). Reading "women": Book club pedagogies and the literary imagination. Journal of Adolescent and Adult Literacy, 50(5), 398-407.

Vyas, S. (2004). Exploring bicultural identities of Asian high school students through the analytical window of a literature club. Journal of Adolescent and Adult Literacy, 48(1), 12-23.

Whittingham, J. L., \& Huffman, S. (2009). The effects of book clubs on the reading attitudes of middle school students. Reading Improvement, 46(3), 130-136. 
Woloshyn, V. E., Lane, L., \& Taber, N. (in press). Using a book club to critique gender and become an engaged reader: It's not just in the "jeans". The Reading Professor, 34(2).

Younger, B. (2003). Pleasure, pain, and the power of being thin: Female sexuality in young adult literature. NWSA Journal, 15(2), 45- 56.

Zipes, J. D. (2002). Sticks and stones: The troublesome success of children's literature from Slovenly Peter to Harry Potter. New York, NY: Routledge. 